\title{
Study on Modularization of Components for Cost Reduction of Sail Yacht Steering System
}

\author{
Young-Hun Kim® \\ ${ }^{1}$ Professor, Department of Naval Architecture and Ocean System Engineering, Kyungnam University, Changwon, Korea
}

KEY WORDS: Sail yacht, Steering system, Modularization, Cost reduction, Productivity improvement

\begin{abstract}
This study aims to improve the price competitiveness of a steering system with a relatively high cost portion among sail yacht components. Hence, the components of the steering system were analyzed, and steering system modularization was proposed. The fabrication processes before and after the application of modularization was presented. For modularization, primary components such as the pedestals and quadrants of the steering system were developed, and the structural safety of the components was reviewed. It was confirmed that the manufacturing cost of the developed steering system decreased by approximately 33\% compared with the existing system. The new steering system presented herein is expected to contribute to the localization of components and price competitiveness of sail yachts.
\end{abstract}

\section{Introduction}

An increase in national income generally increases the level of interest in marine leisure activities and the demand for vessels used for such activities. As sale yachts approximately $30 \mathrm{ft}$ in length have recently gained global popularity, many of these vessels have been manufactured in many countries, including South Korea. International competitiveness in sale yacht manufacturing can be achieved only through the satisfaction of conditions related to exterior design and price competitiveness based on the performance and price of fittings and production process efficiency. A steering system is an essential vessel device for marine navigation; it is connected to a rudder to enable an operator to control the direction of the vessel. Both the steering system and sails are main vessel equipment that require the operator to control them appropriately with less power applied (Song et al., 2017). Although the steering system serves as the core facility for sail yachts, South Korean manufacturers have primarily imported most components of these systems, such as the pedestals, sheaves, chain gears, and quadrants have been imported. The steering system requires a considerable amount of time and labor for its installation in the body of a sail yacht owing to connections to various components, such as those mentioned above. Hence, its price competitiveness is affected significantly. In this study, methods for improving the structural stability and functionality of existing steering systems and reducing the cost of these systems based on their characteristics were investigated. Accordingly, a steering system modularization method based on the development of components that can replace imported components for reducing manufacturing cost and increasing productivity during production is proposed. In addition, it is confirmed that the proposed method increased the price competitiveness of the developed steering system and its technological competitiveness through performance enhancement.

\section{Structure and Modularization of Steering Systems}

\subsection{Overview of Steering Systems}

Steering systems in sail yachts are devices connected to rudders and are used to change the direction of the vessels. They are classified into tiller- and wheel-based steering systems based on steering methods. Furthermore, they can be categorized into single- and twin-wheel steering systems according to wheel operation methods (Miyata et al., 1998/2006). Fig. 1 shows the process of operating a steering wheel system. When the steering wheel is rotated to change the direction of the sail yacht, the torque from the wheel is transmitted to a rudder and used to change the direction of the sail yacht. The components involved in transmitting the wheel torque to the rudder include a steering wheel, cable sheave, bulkhead, quadrant, and a rudder on a steering stand.

Received 4 November 2020, revised 29 November 2020, accepted 3 December 2020

Corresponding author Young-Hun Kim: +82-55-249-2686, younghun@kyungnam.ac.kr

(c) 2020, The Korean Society of Ocean Engineers

This is an open access article distributed under the terms of the creative commons attribution non-commercial license (http://creativecommons.org/licenses/by-nc/4.0) which permits unrestricted non-commercial use, distribution, and reproduction in any medium, provided the original work is properly cited. 

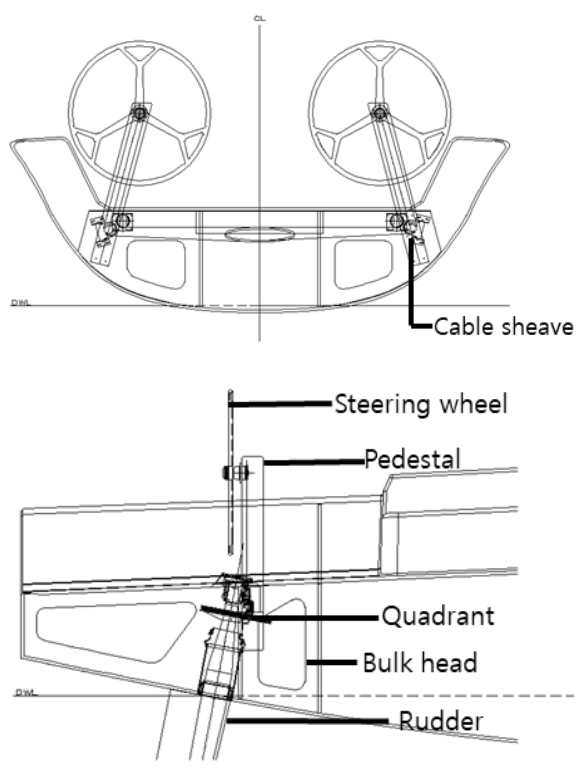

Fig. 1 Component of steering system of sail yacht

However, existing steering systems are technically inefficient in terms of torque transmission and manufacturing. Specifically, indirect steering methods based on cables reduce the torque transmission efficiency. Most components of existing steering systems are imported from other countries and are additionally processed and assembled. However, it is difficult to install a steering system based on these components owing to the complex system structure. Moreover, all the components require additional assembly processes and space for the process. In addition, the import of the components of the steering system used in a sail yacht of approximately $30 \mathrm{ft}(9.14 \mathrm{~m})$ in length incurs approximately $11,000,000 \mathrm{KRW}$ including tariffs. Such an amount of import expense accounts for $5 \%$ to $6 \%$ of the entire sail yacht production cost.

\subsection{Steering System Modularization}

The bulkheads, pedestals, and sheaves of existing steering systems are separate from each other and hence must be connected for installation. In other words, a certain amount of time and labor are required for the sequential assembly of these components. However, the modularization of these components facilitates the assembly of components based on a bulkhead in advance and renders installation for connecting these components unnecessary. Fig. 2 shows the conceptual diagrams of an existing steering system assembled based on imported components and a steering system assembled through modularization.

When the components of a steering system are modularized, pedestals are bolted and fixed to bulkheads. Consequently, processes for fixing pedestals and decks at their correct locations are not required in this method, unlike the existing method. Moreover, plates used for the fixture of sheaves need not be manufactured additionally because these components are directly installed on the bulkheads. Hence, processes for producing and installing plates for the fixture of sheaves

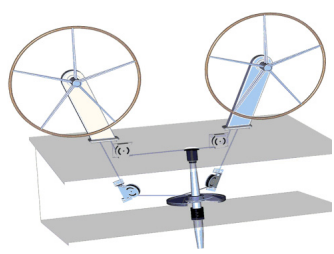

(a) Before modularization
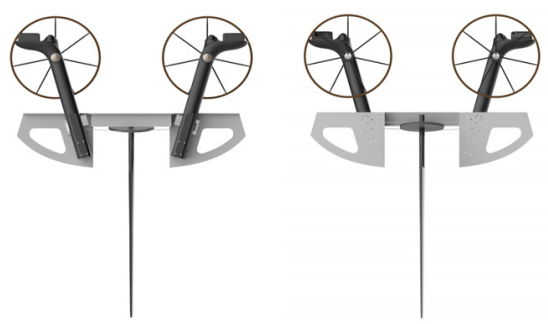

(b) After modularization

Fig. 2 Comparison of the before and after modularization of steering system

can be eliminated. Accordingly, such process change can reduce the number of installation tasks in confined spaces, increase productivity, and decrease factors that might cause quality issues. However, as the form of existing pedestals imported from other countries is inappropriate for the component modularization, it should be redesigned accordingly.

\subsection{Comparison of Processes Before and After Steering System Modularization}

Table 1 lists the assembly and production processes of the steering system before and after modularization. During yacht manufacturing, steering system installation begins with bulkhead installation, followed by deck mounting, and installation of main components of the steering system, such as thee pedestal, sheave, quadrant, rudder, wheel, and cable.

The steering system modularization replaces the existing process of pedestal bonding with direct pedestal bolting, thereby eliminating the processes of fixing pedestals for bonding and producing plates for these components as well as the processes of producing and bonding plates for connecting blocks. Consequently, six to twelve stages of the existing steering wheel installation process before modularization become unnecessary, and the number of stages required for steering wheel installation is reduced from 16 to 9 after modularization. The modularization method reduces the amount of installation time by approximately $5 \mathrm{~d}$ and that of man hours by $20 \mathrm{MH}$ based on a decrease in work time and loss caused by the waiting time for $\mathrm{CNC}$ (Computerized numerical control) processing and resin curing. Furthermore, it increases the productivity of steering system installation and curtails the number of main and subsidiary materials. Additionally, it is expected to ultimately improve the performance and quality of the steering system through increased installation precision and joint quality via the adjusted pedestal joint method. 
Table 1 Comparison of before and after steering system modularization

\begin{tabular}{|c|c|}
\hline & Produc \\
\hline $\begin{array}{l}\text { When } \\
\text { modularizati } \\
\text { on is not } \\
\text { applied }\end{array}$ & $\begin{array}{l}\text { 1. Bulkhead installation } \\
\text { 2. Deck mounting } \\
\text { 3. Pedestal body processing } \\
\text { 4. Deck hole processing } \\
\text { 5. Panels production to fix pedestal deck } \\
\text { 6. Fixing plates to pedestal angle } \\
\text { 7. Pedestal deck bonding } \\
\text { 8. Making plates for installation of connecting } \\
\text { block of housing including sheave } \\
\text { 9. Plates bonding (left) } \\
\text { 10. Platesl bonding (right) } \\
\text { 11. Laminated reinforcement with glass fiber above } \\
\text { and below the plate joint (left) } \\
\text { 12. Laminated reinforcement with glass fiber above } \\
\text { and below the plate joint (right) } \\
\text { 13. Block connection and sheave assembly } \\
\text { 14. Rudder and quadrant assembly } \\
\text { 15. Wheel assembly } \\
\text { 16. Cable connecting }\end{array}$ \\
\hline $\begin{array}{c}\text { When } \\
\text { applying } \\
\text { modularizati } \\
\text { on }\end{array}$ & $\begin{array}{l}\text { 1. Bulkhead modular installation } \\
\text { 2. Deck mounting } \\
\text { 3. Pedestal body processing } \\
\text { 4. Deck hole processing } \\
\text { 5. Pedestal and bulkhead bolting through the deck } \\
\text { 6. Block connection and sheave assembly } \\
\text { 7. Rudder and quadrant assembly } \\
\text { 8. Wheel assembly } \\
\text { 9. Cable connecting }\end{array}$ \\
\hline
\end{tabular}

\subsection{Development of Components and Replacement of Imported Components}

Existing pedestals imported from other countries cannot be connected with the bulkheads through bolting in the proposed steering system modularization method. Hence, a pedestal was redesigned and manufactured. Additionally, other components such as the quadrant, steerer, and cable sheave were developed for cost reduction.

\subsubsection{Pedestal}

The exterior of the pedestal was designed by a professional design company based on the result of a survey conducted based on yacht users to increase practicality and esthetic satisfaction. It was manufactured with carbon to ensure durability. As shown in Fig. 3(a), its length was extended with a bulkhead for bolting. An interference section was removed to prevent interference by sheaves, and an resin infusion process was applied.

\subsubsection{Quadrant}

A quadrant was manufactured via resin transfer molding, and 11 molds were used for its complex form, as shown in Fig. 3(b). The molds were cast with aluminum because this material is unlikely to be

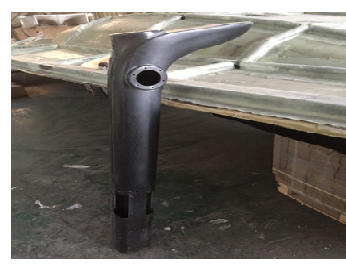

(a) Pedestal

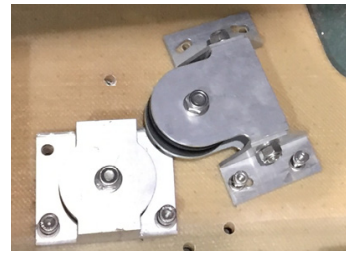

(c) Cable sheaves

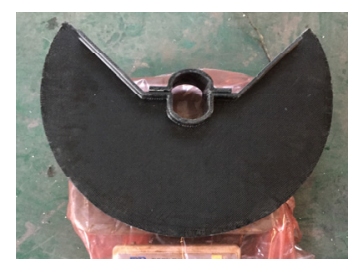

(b) Quadrant

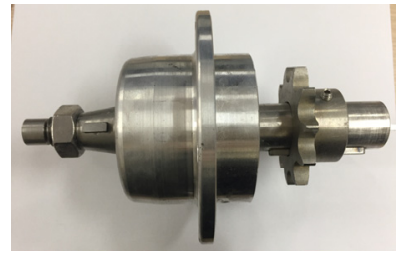

(d) Steerer
Fig. 3 Components of steering system developed for substituting imported components

transformed by heat during heat curing, and it facilitates fine and detailed processing. The quadrant was produced using highly durable carbon.

\subsubsection{Cable sheave}

A sheave for rotating a cable and its housing for bolting using a bulkhead were designed and manufactured, as shown in Fig. 3(c). They were produced using AL6061 owing to its favorable structural strength.

\subsubsection{Steerer}

A steerer used as a rotation gear for a steering wheel can halt the rotation of a steering wheel, and a chain gear that can be connected with a chain. This component was manufactured using SUS316 to ensure corrosion resistance and strength against seawater, and its housing was produced using AL6061. In addition, a retainer was inserted to prevent the inflow of seawater.

\section{Structural Evaluation of Steering System Applying Modularization Method}

\subsection{Review of Mechanism of Developed Steering System}

The mechanical mechanism for force transmission in the developed steering system is based on the order of the steering wheel, chain, cable sheave, cable, quadrant, and rudder. Specifically, components such as the steering wheel, chain, cable, and rudder are used to transfer force directly. Components such as the cable sheave and quadrant serve as media for facilitating more flexible direction adjustments during force transmission. The ultimate force refers to pressure loads represented as a head applied to the rudder in the sea (ISO, 2009). The rudder is constantly affected by dynamic loads during the navigation of sail yachts, including static loads from the surface of water on which the rudder is placed, dynamic loads under the wave loads applied, loads that might occur because of the sailing velocity of the sail yacht, 

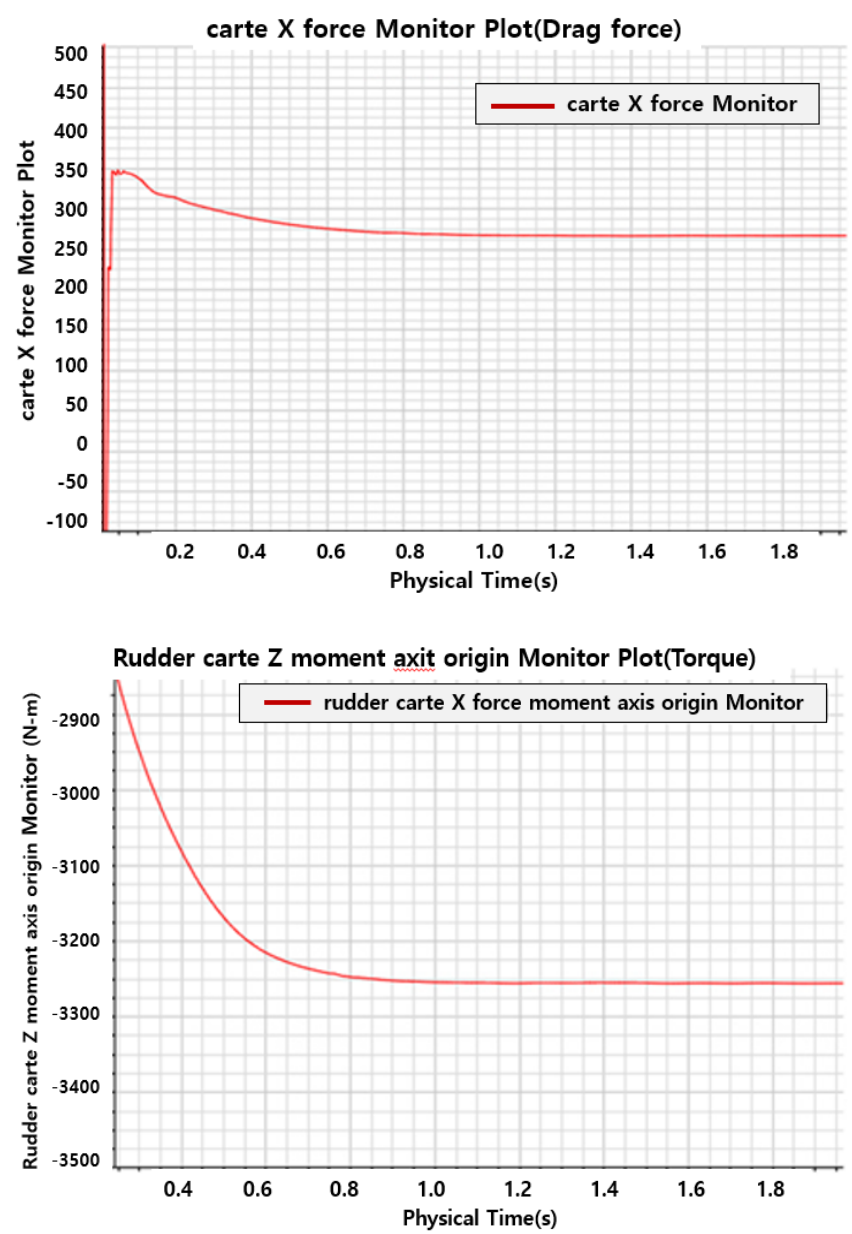

Fig. 4 Result of drag force and torsional load

Table 2 Materials of steering system components

\begin{tabular}{cccc}
\hline Components & $\begin{array}{c}\text { Carbon } \\
\text { (Uni-D) }\end{array}$ & $\begin{array}{c}\text { Multiaxial } \\
\text { fiberglass } \\
\text { (E-Glass) }\end{array}$ & $\begin{array}{c}\text { PVC } \\
\text { foam }\end{array}$ \\
\hline $\begin{array}{c}\text { Bulkhead module } \\
\text { Pedestal }\end{array}$ & $\bullet$ & $\bullet$ & $\bullet$ \\
Quadrant & $\bullet$ & $\bullet$ & \\
Sheave & & Aluminum (AL6061) & \\
\hline
\end{tabular}

and loads caused by tidal currents (Marchaj, 1996). However, loads caused by tidal currents were assumed to be insignificant and hence disregarded in this study. Considering the constant and complex effects of the aforementioned loads, the structural safety of the developed steering system was analyzed under a sail yacht speed of $7.8 \mathrm{kn}(14.4 \mathrm{~km} / \mathrm{h})$ and a rudder angle of $13^{\circ}$, in which the most significant effects of loads were applied. At this time, the surface area and depth of the rudder were set at $1,153,388.2 \mathrm{~mm}^{2}$ and $1,775 \mathrm{~mm}$, respectively.

The drag force and torque were calculated to be $266 \mathrm{~N}$ and 3,256 $\mathrm{N} \cdot \mathrm{m}$, respectively, under the conditions as shown in Fig. 4. Moreover, it was analyzed that the bulkhead module connected to the pedestal supporting the steering system and the body of the sail yacht were safe in terms of its structure and material. Table 2 shows the types of materials used for the components of the developed steering system.

\subsection{Structural Safety Evaluation of Quadrants}

The structural stability of the quadrant was evaluated based on loads transferred to the quadrant connected to the rudder when the maximum load was applied to the rudder. The material properties of the quadrant were identified through a specimen test, in which the yield strength and density were calculated to be $381 \mathrm{~N} / \mathrm{mm}^{2}$ and $1.538 \mathrm{~g} / \mathrm{cm}^{3}$, respectively. Moreover, a structural analysis was performed based on a commercial analysis program, Abaqus. As for the modeling conditions, the number of nodes was established as 42,709 , number of elements as 26,400 , and rotation torque in the Z-direction considering external loads as $3,256 \mathrm{~N} \cdot \mathrm{m}$.

Boundary conditions for the structural analysis were established as follows. First, a reference point (RP) was set in the center of the model, and kinematic coupling was applied to the inner wall. The displacement and rotation in all directions, except rotation in the Z-direction, based on the RP were restricted as constraints for setting the loads and boundary conditions. To restrict the displacement caused by inertial force in the tangential direction to the circumference, only the Y-direction was restricted through the establishment of a local coordinate system for the tangential direction (refer to Fig. 5.)

The analytical result indicated that the stress applied to the quadrant occurred at the part connecting the quadrant and rudder. The maximum tensile strength of the quadrant was calculated to be $278.6 \mathrm{~N} / \mathrm{mm}^{2}$, which was lower than its yield strength of $381 \mathrm{~N} / \mathrm{mm}^{2}$. Therefore, this component was evaluated to be structurally safe (refer to Fig. 6.)
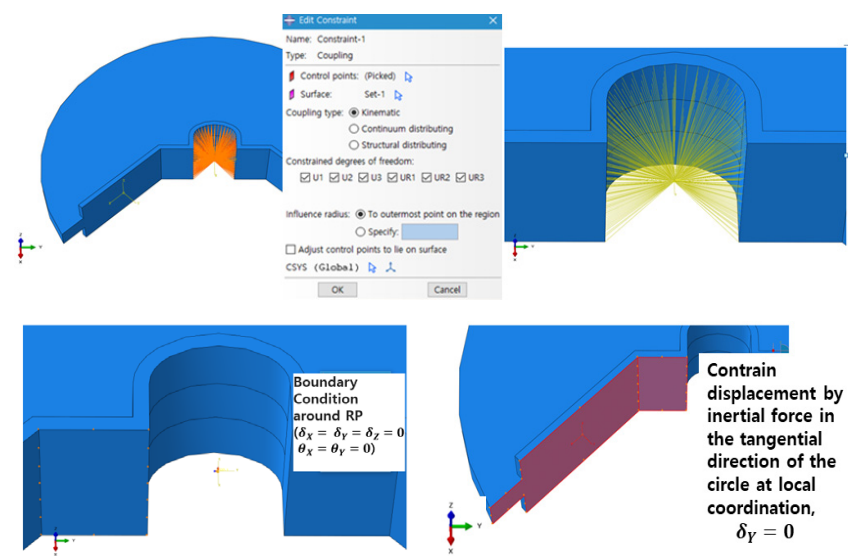

Fig. 5 Boundary conditions of modeling
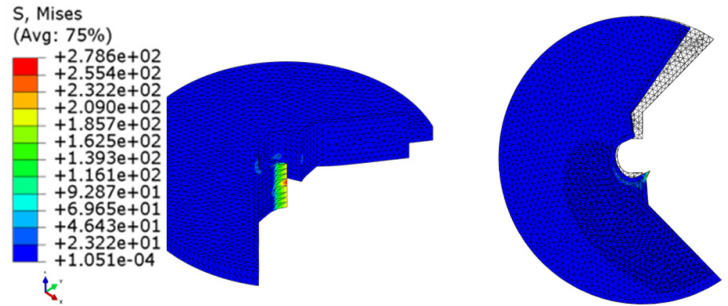

Fig. 6 Stress distribution of quadrant 


\section{Review of Manufacturing Cost of Steering System Before and After Modularization}

The difference in manufacturing cost of the steering system before and after the development of its components and modularization is as follows. Before steering system modularization, only the purchasing cost for imported components was incurred. After steering system modularization, the mold casting cost, which is considered an initial investment cost for component manufacturing, material cost for component manufacturing, and labor cost were incurred owing to the manufacturing and installment of components developed in this study. However, the entire cost for steering system manufacturing after steering modularization was calculated to be lower than that based on imported components, as will be explained in detail below. The mold casting cost can be offset from the second cycle of manufacturing, in that additional cost reduction can be achieved through mass manufacturing, Moreover, steering system modularization resulted in a decrease in the number of processes for steering system installment, cost for materials (such as plates for fixing the pedestal, and fiber and resin for fixing sheaves, which are required in the existing method), work time, and waiting time for $\mathrm{CNC}$ processing and resin curing.

Table 3 shows the cost calculated for the reduced production process and material cost. When the existing purchasing cost for imported components was converted to 100 , the total amount of material cost and labor cost for manufacturing the components developed in this study was calculated to be 76.7. The labor cost was calculated based on the man hours required for the assembly of components. Moreover, the work time reduced by approximately $5 \mathrm{~d}$ owing to the reduced production processes. Subsequently, the amount of reduced cost such as the labor cost was calculated to be 9.8 . When the reduced amount

Table 3 Cost comparison of before and after modularization

\begin{tabular}{|c|c|c|}
\hline Case & \multicolumn{2}{|c|}{ Production cost ratio $(\%)$} \\
\hline \multirow{5}{*}{$\begin{array}{l}\text { When installing existing } \\
\text { imported products and } \\
\text { not applying } \\
\text { modularization }\end{array}$} & \multicolumn{2}{|c|}{ Pedestal: 57.9} \\
\hline & \multicolumn{2}{|c|}{ Quadrant: 9.1} \\
\hline & \multicolumn{2}{|c|}{ Cable sheaves: 10.7} \\
\hline & \multicolumn{2}{|c|}{ Steerer: 12.1} \\
\hline & \multicolumn{2}{|c|}{ Transportation: 10.9} \\
\hline \multirow{11}{*}{$\begin{array}{l}\text { When installing products } \\
\text { developed and } \\
\text { modularization } \\
\text { application }\end{array}$} & \multicolumn{2}{|c|}{ Total: 100} \\
\hline & \multirow{5}{*}{ material cost } & Pedestal: 17.1 \\
\hline & & Quadrant: 4.0 \\
\hline & & $\begin{array}{c}\text { Cable sheaves: } 7.1 \\
\text { Steerer: } 17.1\end{array}$ \\
\hline & & Al mold: 1.4 \\
\hline & & FRP mold: 4.7 \\
\hline & \multirow{4}{*}{ Labor costs } & Pedestal: 17.0 \\
\hline & & Quadrant: 7.7 \\
\hline & & Cable sheaves: 0.3 \\
\hline & & Steerer: 0.3 \\
\hline & \multicolumn{2}{|c|}{ Total: 76.7} \\
\hline
\end{tabular}

1 man-hour $=16,700 \mathrm{KRW}$ (assumed)

1 Euro $=1,302 \mathrm{KRW}$ application

Import prices were confirmed by domestic companies was applied to 76.7 , the ultimate cost required for the steering system manufactured using the proposed method was calculated to be 66.9. Therefore, the entire cost for sail yacht manufacturing after steering system modularization was reduced by approximately $33 \%$ compared with that based on the imported components. In addition, the steering system manufacturing cost is expected to reduce even further by applying steering system modularization based on the components developed in this study, considering the increased structural strength of the developed quadrant compared with that of imported quadrants based on materials, tariffs for imported components, and other expenses.

\section{Conclusions}

The difference in the steering system of a sail yacht before and after the modularization of its steering system components was analyzed in this study. The findings of this study are as follows:

(1) In the steering system manufacturing process, the number of stages for the installation process was reduced from 16 to 9 after modularization considering steering system operation. Seven stages of $\mathrm{CNC}$ processing, plate and fixture manufacturing, and bonding were eliminated, and the required amount of man hours and work time decreased through such a process. The performance of the steering system improved after replacing the existing bonding-based pedestal fixture method to the developed mechanical pedestal fixture method.

(2) As the imported pedestals were not suitable to be used in the developed steering system modularization method, a new pedestal was developed in this study and resulted in cost reduction. Furthermore, a steering wheel, steerer, and cable sheave were developed in this study and resulted in cost reduction. A structural analysis based on the developed components was performed, and structural safety of these components was confirmed through the analysis.

(3) The cost for steering system manufacturing after modularization reduced by approximately $33 \%$ compared with that based on imported components in single steering system manufacturing although an initial mold casting cost for component development was incurred. Furthermore, because the amount of time required for sail yacht manufacturing decreased by approximately $5 \mathrm{~d}$, the steering system modularization method was confirmed to be effective in terms of production cost and productivity. In addition, it was superior to the existing methods using imported components, as its mold casting cost can be offset from the second cycle of steering system manufacturing through mass production.

\section{References}

Miyata, H., Yokoyama, E., Dakahashi, D., \& Nagai, J. (2006). Science of Yacht (Hong, S.W., Kim, S.S., Kim, H.C., Lee, S.H., Lee, Y.G., Kim,Y.J., Kim, \& S.H., Trans.). Soeul, Korea : Jisungsa. (Original Work Published in 1998, Japan: Senkyo Company).

ISO. (2009). Hull Construction and Scantlings-Rudders (ISO 12215-8) 
Song, Y.H., Kim, D.J., Chang, S.R., Lee, Y., \& Min, K.C. (2017). Research on Arrangement Design for Sailing Yacht Winch using 3D Human Simulation. Journal of Ocean Engineering and Technology, 31(6), 419-424. https://doi.org/10.26748/KSOE. 2017.12.31.6.419

Marchaj, C.A. (1996). Sail Performance: Techniques to Maximize Sail Power. London : UK Adlard Coles Nautical.
Author ORCID

Author name

ORCID

Kim, Young Hun

0000-0002-3072-6852 